ORIGINAL ARTICLE

\title{
A prospective study for Assessment of saliva CA- 125 level in oral cancer patients
}

\author{
ARAFAT AHMAD ${ }^{1}$, USAMA BIN GHAFFAR ${ }^{2}$, SANKET DADARAO HIWARE ${ }^{3}$, MOHAMMED TAHER ALI $^{4}$, SAMINA WASI $^{5}$ \\ ${ }^{1}$ Assistant Professor, Department of Biochemistry, College of Medicine Imam Abdulrahman Bin Faisal University, Dammam, Saudi Arabia. \\ Email: aaahmad@iau.edu.sa \\ ${ }^{2}$ Assistant professor, Department of Pathology, College of Medicine, Majmaah University, Al Majma'ah, Saudi Arabia. Email: \\ ubghaffar@gmail.com \\ ${ }^{3}$ Assistant professor, Department of Anatomy, College of Medicine, Imam Abdulrahman Bin Faisal University, Dammam, Saudi Arabia \\ Email: sdhiware@iau.edu.sa (corresponding author) \\ ${ }^{4}$ Associate professor, Department of Pharmacology, College of Clinical pharmacy, Imam Abdulrahman Bin Faisal University, Dammam, \\ Saudi Arabia. Email: mtali@iau.edu.sa \\ ${ }^{5}$ Assistant Professor, Department of Biochemistry, College of Medicine, Imam Abdulrahman Bin Faisal University, Dammam, Saudi Arabia. \\ Email: Skiasi@iau.edu.sa \\ Corresponding Author: Dr. Sanket Dadarao Hiware, Assistant professor, Department of Anatomy, College of Medicine, Imam Abdulrahman \\ Bin Faisal University, Email: sdhiware@iau.edu.sa
}

\begin{abstract}
Aim: To detect CA- 125 level in saliva of oral cancer patients.

Methodology: A total of fifty- six SCC patients and thirty healthy subjects were selected. A non- stimulated whole saliva (5cc) was collected and evaluated for CA- 125 level ELISA.

Results: A higher salivary CA 125 level $(514.2 \pm 132.6 \mathrm{U} / \mathrm{mL})$ was observed in poorly differentiated SCC followed by moderately differentiated $(340.6 \pm 80.2 \mathrm{U} / \mathrm{mL})$ and minimum values was observed in well differentiated SCC (236.2 $\pm 76.2 \mathrm{U} / \mathrm{mL})$. The mean \pm SD CA- 125 level in group I patients was $428.5 \pm 110.2 \mathrm{U} / \mathrm{mL}$ and in group II was 132.4 $\pm 58.6 \mathrm{U} / \mathrm{mL}$. Higher salivary CA 125 level $(520.5 \pm 168.4 \mathrm{U} / \mathrm{mL})$ was observed in stage IV and minimum in stage I $(165.2 \pm 46.2 \mathrm{U} / \mathrm{mL})$ which was statistically significant $(P<0.05)$.

Conclusion: Patients with poorly differentiated SCC, cases of buccal mucosa and stage IV exhibited higher values of salivary CA- 125 level as compared to healthy control.

Key words: Oral Cancer, Saliva, Tongue, CA- 125
\end{abstract}

\section{INTRODUCTION}

Oral cancer is major reason of death. It is the second highly prevalent head and neck cancer having high deaths and morbidity in males and third in females after lung cancer. Oral cancer patients have 5 years mortality of $50 \% .{ }^{1}$ Among all cancer of mouth, oral squamous cell carcinoma (OSCC) is the most common one. Dorsum and lateral border of tongue, mouth floor, lips, buccal mucosa, alveolus, pharynx and gingiva are potential site of its occurrence. ${ }^{2}$ Depending upon the geographical area, it has specific site of origin. Asian population has high tendency of involvement of buccal mucosa while Europeans and American show tongue as commonest site. Tobacco and alcohol are causative agent for SCC. ${ }^{3}$

The high prevalence of SCC in Indian and Pakistan is due to increased rate of alcohol consumption and tobacco usage in various forms such as chewing and non- chewing tobacco. Gutkha, Pansupari, Zarda, betel quid, mawa, mishri are various non- smoking forms of tobacco whereas bidi, cigarette, hukli, hookah, cigar are smoking forms of tobacco. ${ }^{4}$ The occurrence of SCC depends on intensity and frequency of tobacco products usage. The peak age range is above 45 years. However, in the last couple of years young individuals also show increase incidence owing to high tobacco consumption in this age group. ${ }^{5}$

Tumour markers are produced by either tumour or host against tumour in the secretions. There are various forms of tumour markers such as enzymes, proteins and hormones etc. Common secretion where these markers are found are saliva, blood, urine and other tissues. Thus, saliva may be regarded as a diagnostic aid to detect tumour markers for SCC because it is safe, simple, non- expensive, painless and non- invasive method. ${ }^{6}$ Cancer antigen (CA-125) is widely used tumour marker in SCC. 5 to $80 \mathrm{U} / \mathrm{ml}$ is normal value for CA- 125 . Outer surface of cancer cells sheds CA 125 into saliva and blood. SCC patients exhibit higher CA- 125 level. ${ }^{7}$ Considering this, we attempted present study with the aim to detect CA- 125 level in saliva of SCC patients.

\section{METHODOLOGY}

This cross- sectional observation study was conducted following approval from review and ethical committee with written informed consent from all patients as well as healthy subjects. Patient consent followed declaration of Helsinski. The study duration was of 8 months. Patients above 18 years irrespective of sex with written consent were selected. Patients with psychiatric disorder, pregnant women etc. were excluded.

Fifty- six SCC patients and thirty healthy subjects were selected. Grouping was done as group I comprised of SCC patients and group II as control (healthy). Histological grading as well differentiated, moderately differentiated and poorly differentiated was performed. Staging of OSCC was also done.

Estimation of CA- 125: A non- stimulated whole saliva $(5 c c)$ was collected in wide mouth container from all subjects. It was subjected to centrifugation for 10 minutes at $3000 \mathrm{rpm}$. Resultant supernatant fluid was separated and evaluated for CA- 125 level using enzyme-linked immunosorbent assay (ELISA) using the CA125 quantitative assay kit.

Statistical analysis: All findings of the study were represented as mean, numerical and percentages. SPSS 
version 20.0 was used for the study. One way ANOVA test compared CA- 125 values between various groups and subgroups. The level of significance $<0.05$ was considered significant.

\section{RESULTS}

Table 1 Clinical characteristics

\begin{tabular}{|l|l|l|}
\hline Variables & Number & Percentage \\
\hline Age group & & \\
\hline $20-30$ & 7 & 12.5 \\
\hline $30-40$ & 25 & 44.6 \\
\hline $40-50$ & 14 & 25 \\
\hline $50-60$ & 10 & 17.8 \\
\hline Site & & \\
\hline Labial mucosa & 3 & 5.3 \\
\hline Buccal mucosa & 32 & 57.1 \\
\hline Tongue & 15 & 26.7 \\
\hline Palate & 2 & 3.6 \\
\hline Alveolar ridge & 3 & 5.3 \\
\hline Lips & 1 & 1.8 \\
\hline Gender & & \\
\hline Male & 42 & 75 \\
\hline Female & 14 & 25 \\
\hline Grading & & \\
\hline Well differentiated & 10 & 17.8 \\
\hline Moderately differentiated & 26 & 46.4 \\
\hline Poorly differentiated & 20 & 35.7 \\
\hline Stage & & \\
\hline I & 8 & 14.2 \\
\hline II & 11 & 19.4 \\
\hline III & 20 & 35.7 \\
\hline IV & 17 & 30.3 \\
\hline & & \\
\hline & & \\
\hline & & \\
\hline
\end{tabular}

Maximum cases were presented in age group 30-40 years ie 25 (44.6\%) followed by $40-50$ years 14 (25\%), 5060 years $10(17.8 \%)$ and $20-30$ years $7(12.5 \%)$. Common site was buccal mucosa $32(57.1 \%)$, tongue $15(26.7 \%)$, labial mucosa $3(5.3 \%)$, alveolar ridge $3(5.3 \%)$, palate 2 $(3.6 \%)$ and lips $1(1.8 \%)$. There were $42(75 \%)$ males and $14(25 \%)$ females. Gradingwas well differentiated in 10 $(17.8 \%)$, moderately differentiated in $26(46.4 \%)$ and poorly differentiated in $20(35.7 \%)$ cases. Stage was I in 8 (14.2\%), II in 11 (19.4\%), III in 20 (35.7\%) and IV in 17(30.3\%) (Table 1).

Table 2 Salivary CA 125 levels

\begin{tabular}{|l|l|l|}
\hline Groups & CA 125 (Mean \pm SD) & P value \\
\hline Group I & $428.5 \pm 110.2$ & Significant $<0.05$ \\
\hline Group II & $132.4 \pm 58.6$ & \\
\hline
\end{tabular}

ANOVA, Significance $<0.05$

\section{Graph 1}

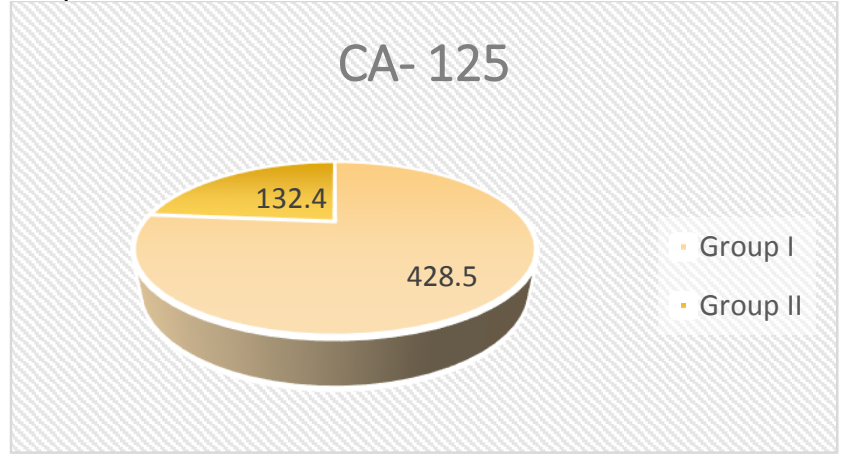

The mean \pm SD CA- 125 level in group I patients was $428.5 \pm 110.2 \mathrm{U} / \mathrm{mL}$ and in group II was $132.4 \pm 58.6 \mathrm{U} / \mathrm{mL}$ which was statistically significant $(P<0.05)($ Table 2 , Graph 1).

Table 3 Salivary CA 125 levels based on staging

\begin{tabular}{|l|l|l|}
\hline Stage & Mean \pm SD & P value \\
\hline I & $165.2 \pm 46.2$ & Significant $<0.05$ \\
\hline III & $270.4 \pm 84.2$ & \\
\hline IV & $384.2 \pm 112.4$ & \\
\hline ANOVA, Signen & $520.5 \pm 168.4$ & \\
\hline
\end{tabular}

ANOVA, Significance $<0.05$

Higher salivary CA 125 level $(520.5 \pm 168.4 \mathrm{U} / \mathrm{mL})$ was observed in stage IV and minimum in stage I (165.2 \pm 46.2 $\mathrm{U} / \mathrm{mL}$ ) which was statistically significant $(\mathrm{P}<0.05)$ (Table 3 , Graph 2).

Graph 2

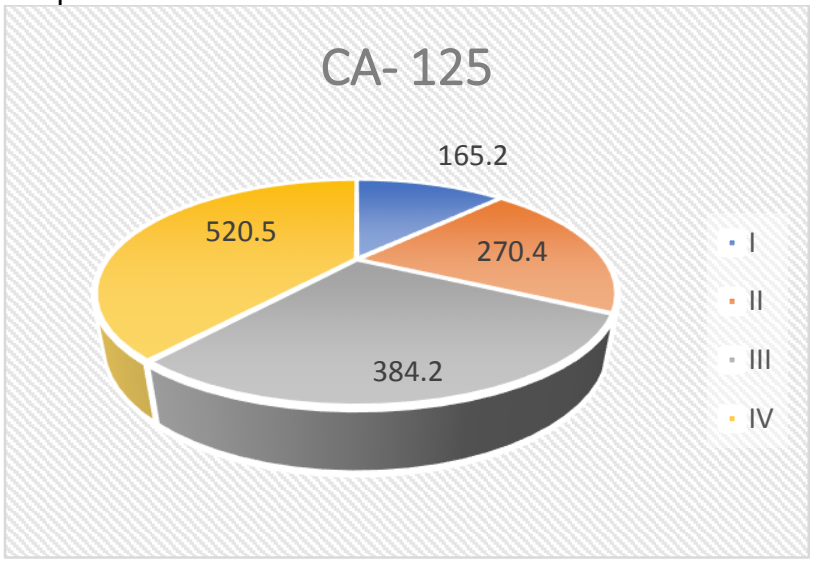

Table 4 Salivary CA 125 levels based on Histopathological grading

\begin{tabular}{|l|l|l|}
\hline Stage & Mean \pm SD & P value \\
\hline Well differentiated & $236.2 \pm 76.2$ & Significant $<0.05$ \\
\cline { 1 - 2 } $\begin{array}{l}\text { Moderately } \\
\text { differentiated }\end{array}$ & $340.6 \pm 80.2$ & \\
\hline $\begin{array}{l}\text { Poorly } \\
\text { differentiated }\end{array}$ & $514.2 \pm 132.6$ & \\
\hline
\end{tabular}

ANOVA, Significance $<0.05$

\section{Graph 3}

CA- 125

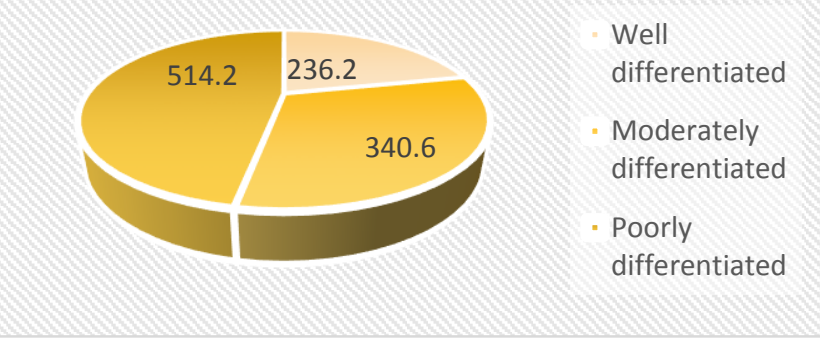

Higher salivary CA 125 level $(514.2 \pm 132.6 \mathrm{U} / \mathrm{mL})$ was observed in poorly differentiated SCC followed by moderately differentiated $(340.6 \pm 80.2 \mathrm{U} / \mathrm{mL})$ and minimum 
values was observed in well differentiated SCC $(236.2 \pm 76.2 \mathrm{U} / \mathrm{mL})$ which was statistically significant $(\mathrm{P}<$ 0.05) (Table 4, Graph 3).

Table 5 Salivary CA125 levels based on different sites

\begin{tabular}{|l|l|l|}
\hline Site & Mean \pm SD & P value \\
\hline Labial mucosa & $356.2 \pm 113.6$ & Significant $<0.05$ \\
\cline { 1 - 2 } Buccal mucosa & $512.0 \pm 124.2$ & \\
\hline Tongue & $386.4 \pm 130.5$ & \\
\cline { 1 - 2 } Palate & $390.2 \pm 132.8$ & \\
\cline { 1 - 2 } Alveolar ridge & $312.6 \pm 165.7$ & \\
\cline { 1 - 2 } Lips & $402.5 \pm 236.2$ & \\
\hline
\end{tabular}

The mean salivary CA- 125 level in SCC patients of labial mucosa was $356.2 \pm 113.6 \mathrm{U} / \mathrm{mL}$, buccal mucosa was $512.0 \pm 124.2 \mathrm{U} / \mathrm{mL}$, tongue was $386.4 \pm 130.5 \mathrm{U} / \mathrm{mL}$, palate was $390.2 \pm 132.8 \mathrm{U} / \mathrm{mL}$, alveolar ridge was $312.6 \pm 165.7$ $\mathrm{U} / \mathrm{mL}$ and lips was $402.5 \pm 236.2 \mathrm{U} / \mathrm{mL}$ which was statistically significant $(P<0.05)$ (Table 5, Graph 4).

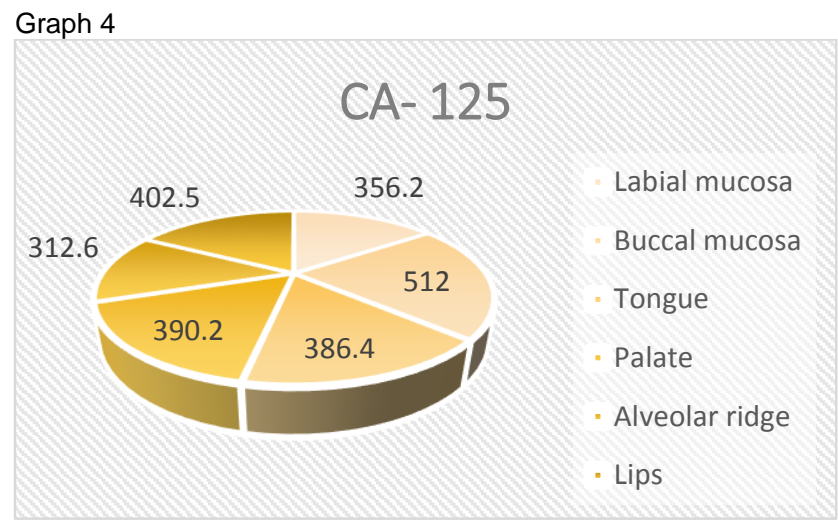

\section{DISCUSSION}

Oral squamous cell carcinoma is the highly prevalent cancer among men especially those who consume tobacco products. Depending upon the type of tobacco product, the location of OSCC is decided. ${ }^{8}$ Patients consuming chewable tobacco ae more prone to SCC of labial mucosa, buccal mucosa and mouth floor and those use smoking form of tobacco (bidi, cigarette) are liable for involvement of palate. Initially potentially malignant disorders like lichen planus, oral submucous fibrosis (OSMF) and leukoplakia appears in the oral cavity. All of them have high malignant potential. Stomatitis nicotina palatinus also known as smokers' palate is associated with bidi and cigarette smoking. ${ }^{9}$ Tobacco pouch keratosis is lesion seen in vestibules such as labial and buccal vestibules. The role of alcohol is to make the oral mucosa dry and permeable to oral carcinogens such as aromatic hydrocarbons, tar and nicotine etc. Once permeability to these agents increases, the penetration of products to deep er tissues is enhanced leading to oral cancer. ${ }^{10}$

Our single centre, randomized study enrolled 56 histological confirmed cases of OSCC and thirty healthy subjects. It was seen that CA- 125 level in SCC patients was $428.5 \pm 110.2 \mathrm{U} / \mathrm{mL}$ and in controls was $132.4 \pm 58.6$ $\mathrm{U} / \mathrm{mL}$. Geng et $\mathrm{al}^{11}$ in their study assessed carcinogen antigen 125 (CA125) in saliva of OSCC patients. The saliva CA125 was significantly higher in patients with OSCC
(498.10 $\pm 125.49 \mathrm{U} / \mathrm{mL})$ than in patients with nonneoplastic disease $(139.26 \pm 125.49 \mathrm{U} / \mathrm{mL})$ and healthy controls (137.12 $\pm 124.58 \mathrm{U} / \mathrm{mL})$. A non- significantly difference existed between all groups $(P>0.05)$.

There were $42(75 \%)$ males and $14(25 \%)$ females in our study. The study by Geng et al $^{11}$ had 97OSCC, 36 patients with nonneoplastic disease and 50 controls. Balan et $\mathrm{al}^{12}$ conducted a study on 60 SCC and 60 healthy subjects. Zini et $\mathrm{al}^{13}$ also observed higher prevalence of males than females in their study. We can suggest that more number of males in our study could be due to the high habit of tobacco consumption in contrast to females.

Our study had maximum cases were presented in age group 30-40 years ie $25(44.6 \%)$ and minimum in age group $20-30$ years $7(12.5 \%)$. Younus et al $^{14}$ conducted study on 138 OSCC patients and 30 normal subjects and found 30-39 years age group (29.7\%) to be mostly affected.

Our study demonstrated that common site was buccal mucosa in $57.1 \%$, tongue in $26.7 \%$, labial mucosa in $5.3 \%$, alveolar ridge in $5.3 \%$, palate in $3.6 \%$ and lips in $1.8 \%$ cases. Younus et $\mathrm{al}^{14}$ found that in $58.0 \%$ cases Buccal mucosa was the commonest site. A study by Balan et al ${ }^{12}$ showed buccal mucosa (24), tongue in 14, palate in 8 , labial mucosa in 6 , floor of the mouth and alveolar ridge in 4 each the most common sites of OSCC.

We found that our patients found to be $10(17.8 \%)$ well differentiated, $26(46.4 \%)$ in moderately differentiated and $20(35.7 \%)$ poorly differentiated. It was seen that most of the patients ie $17(30.3 \%)$ had stage IV, stage I was in 8 (14.2\%), II in 11 (19.4\%) and stage III was seen in 20 $(35.7 \%)$ cases. Younus et $\mathrm{al}^{14}$ found that $37 \%$ had stage III and $40 \%$ had stage IV.

Higher salivary CA 125 level $(520.5 \pm 168.4 \mathrm{U} / \mathrm{mL})$ was observed in stage IV in our study and in poorly differentiated SCC $(514.2 \pm 132.6 \mathrm{U} / \mathrm{mL})$. Our results are in consistency with the results by Younus et $\mathrm{al}^{14}$ where a value of $593.1+57.15 \mathrm{U} / \mathrm{mL}$ and $597.2+60.5 \mathrm{U} / \mathrm{mL}$ were found respectively. Alamgir et $\mathrm{al}^{15}$ found significantly higher salivary CA125 level in OSCC patients than normal individuals and a statistically significant differences was observed among different histopathological grades as detected by ELISA.

The usefulness of saliva as a biological marker has been substantiated by various studies. ${ }^{16,17}$ The diagnosis value of saliva in oral diseases and cancers is well established. The readily availability, non- invasiveness makes saliva the best option. Bast and Colleagues first recognised CA 125 as a transmembrane mucin. It has also been found as a marker in ovarian and breast cancers. ${ }^{18,19,20,21}$

There are few limitations of our study such as the diagnostic ability (Sensitivity/ specificity) of CA- 125 was not assessed. Moreover, the effect of age on level of CA125 was not detected.

\section{CONCLUSION}

Within the limitations of the study, we conclude that patients with OSCC had higher salivary CA- 125 level as compared to healthy control. Poorly differentiated SCC, cases of buccal mucosa and stage IV exhibited higher values. 


\section{REFERENCES}

1. Mehrotra R, Yadav S. Oral squamous cell carcinoma: Etiology, pathogenesis and prognostic value of genomic alterations. Indian Journal of Cancer. 2006;43(2):60.

2. Siegel $R L$, Miller KD, Jemal A. CA Cancer J Clin. 2018;68(1):7-30.

3. Zygogianni AG, Kyrgias G, Karakitsos P. Oral Squamous cell cancer: Early detection and the role of alcohol and smoking. Head Neck Oncol. 2011;3:2-7.

4. Saman DM. A review of the epidemiology of oral and pharyngeal carcinoma: Update. Head \& Neck Oncology. 2012;4(1):1.

5. Lambert $R$, Sauvaget $C$, de Camargo Cancela $M$, Sankaranarayanan R. Epidemiology of cancer from the oral cavity and oropharynx. European Journal of Gastroenterology \& Hepatology. 2011; 23(8):633-41.

6. Scully C, Bagan JV. Recent advances in oral oncology 2008 ; squamous cell carcinoma imaging, treatment and prognostication and treatment outcomes. Oral Oncol. 2009;45(6):25-30.

7. Streckfus CS, Bigler LR. Saliva as a diagnostic fluid. Oral Dis. 2002;8:69-76.

8. Bast Jr RC, Badgwell D, Lu Z, Marquez R, Rosen D, Liu J, Baggerly KA, Atkinson EN, Skates S, Zhang Z, Lokshin A. New tumor markers: CA125 and beyond. International Journal of Gynecological Cancer. 2005;15: 274-81.

9. Biomarkers for Cancer Diagnosis, CA125. Tumor-Associated Antigens: Identification, Characterization, and Clinical Applications. 2009;261-79.

10. Bast Jr RC, Badgwell D, Lu Z, Marquez R, Rosen D, Liu J, Baggerly KA, Atkinson EN, Skates S, Zhang Z, Lokshin A. New tumor markers: CA125 and beyond. International Journal of Gynecological Cancer. 2005;15: 274-81.

11. Geng XF, Du M, Han JX, Zhang M, Tang XF, Xing RD. Saliva CA125 and TPS levels in patients with oral squamous cell carcinoma. The International journal of biological markers. 2013 Apr;28(2):216-20.

12. Balan JJ, Rao RS, Premalatha BR, Patil S. Analysis of tumor marker CA 125 in saliva of normal and oral squamous cell carcinoma patients: A comparative study. J Contemp Dent Pract. 2012;13(5):671-5.

13. Zini A, Czerninski R, Sgan-Cohen HD. Oral cancer over four decades: Epidemiology, trends, histology, and survival by anatomical sites. Journal of Oral Pathology \& Medicine. 2010;39(4):299-305.

14. Younus S, Younus N, Khan HM. Determination of CA 125 Salivary Level with Clinicopathological Characteristics in Oral Squamous Cell Carcinoma in Karachi. Asian Journal of Medicine and Health. 2018 Nov 6:1-9.

15. Alamgir MM, Jamal Q, Mirza T. Conventional clinical and prognostic variables in 150 oral squamous cell carcinoma cases from the indigenous population of Karachi. Pakistan Journal of Medical Sciences. 2016;32(3):672.

16. Nagler R, Bahar G, Shpitzer T, Feinmesser R. Concomitant analysis of salivary tumor markers-a new diagnostic tool for oral cancer. Clin Cancer Res 2006; 12: 3979-84.

17. Nagler RM. Saliva as a tool for oral cancer diagnosis and prognosis. Oral Oncol 2009; 45: 1006-10.

18. Bast RC, Feeney M, Lazarus HE, Nadler LM, Colvin RB, Knapp RC. Reactivity of a monoclonal antibody with human ovarian carcinoma. The Journal of Clinical Investigation. $1981 ; 68(5): 1331-7$.

19. Plante M, Wong GY, Nisselbaum JS. Relationship between saliva and serum CA 125 in women with and without epithelial ovarian cancer. Obstet Gynecol 1993 Jun;81(6):989-92.

20. Agha-Hosseini F, Mirzaii-Dizgah I, Rahimi A. Correlation of serum and salivary CA125 levels in patients with breast cancer. J Contemp Dent Pract 2009 Nov 1;10(6):E001-08.

21. Tay SK, Chua EK. Correlation of serum, urinary and salivary CA 125 levels in patients with adnexal masses. Ann Acad Med Singapore 1994 May;23(3):311-14 